\title{
A Phono-Rhetorical Study of Oronyms in English
}

\author{
Department of English, \\ Faculty of Languages, \\ University of Kufa, Iraq
}

Siham Mohammed Hasan Alkawwaz

DOI: https://doi.org/10.36941/ajis-2021-0044

\begin{abstract}
Oronym is a kind of wordplay where phrases that sound the same are comically used. This study investigates oronyms in English by analyzing their phonological aspects employed to make rhetorical effect, exploring their production mechanism, and constructing a phono-rhetorical model for analyzing them. Twelve examples of oronyms have been randomly taken from TV shows, songs, nursery rhymes, and books of jokes and fun with words. The main findings of the study have been: (1) Oronym is a rhetorical device that combines two ideas in a single sequence of words; (2) Oronyms are constructed on the basis of juncture by which the same sequence of sounds can form more than one morphemic structure; (3) juncture acts as a linguistic strategy consciously used to yield phonological ambiguity necessary for such type of wordplay; and (4) there are two main types of oronyms - Word-to-Phrase and Phrase-to-Phrase - that can be utilized vertically and horizontally. The significance of this study stems from its novelty and being an earnest endeavour to explore the linguistic features of oronyms comprehensively. It laid a theoretical foundation for promising future studies on oronyms even in other languages, especially in Arabic.
\end{abstract}

Keywords: oronyms, juncture, homophonic phrases, wordplay, ambiguity, pun

\section{Introduction}

Oronym is a new term used in recreational linguistics to designate phrases and sentences read or heard in two ways with the same sound for comical effect. It was first coined by Gyles Brandreth and published in his book The Joy of the Lex (1980). An example of such an oronymic use of language is the play on the titles and imaginary authors of books, as in (Keep Fit by Jim Nastics/ Gymnastics) or (Hospitality by Collin Anytime/ call in any time). Oronyms have been scarcely researched and seldom referred to in most dictionaries of linguistic and literary terms except for some remarks in a few books, such as Stewart (1990, 2015); Pinker (1994); Evans (2012), and Joshi (2014). The scant research in this domain may be attributed to several reasons. Firstly, this kind of wordplay is uncommon in comparison to others. For Nash (1985: 139), it is so because there are rare instances of "homophonic phrases which are, unlike homophones, not readily available in the stock of the language but have to be forced". Ermida (2008: 42) concurs with Nash's opinion that "such phrases are much rarer to occur than homophonic words and rarely occur and require a greater degree of imagination to be created and of attention to be detected".

Secondly, there is a lack of consensus among scholars on naming such wordplay genre. Although 
the term "oronym" was devised in 1980, scholars have referred to it by different labels, such as homophonic phrases puns (Nash, 1985:139); syllabic phenomenon based on playing with word boundaries (Chiaro, 1992); and phonetic puns (Ermida, 2008).

Thirdly, less attention has been given to oronyms and the linguistic phenomena related to them, as emphasized by various scholars. For instance, phonological ambiguity has been the less studied than other types of ambiguity because many authors place ambiguity into lexical and syntactic categories, leaving out the phonological component (Attardo, 1994 and Attardo et al. 1994) or regard it as a subtype of lexical ambiguity (Richard et al., 1985 and Bussmann, 1996). Moreover, juncture has not been investigated enough as a rich source of phonological ambiguity used to play and make fun with words (Alkawwaz, 2020).

Consequently, oronyms have been overlooked in most wordplay studies. Therefore, this study seeks to examine oronyms thoroughly in English by analyzing their phonological aspects meant to make rhetorical effect. The study also aims to investigate the nature of oronyms, explore their production mechanism and analyze their phonological and rhetorical aspects, by answering these questions:

1. What is the inclusive definition of oronym?

2. Is oronym a homophone, a juncture, or a different linguistic concept?

3. Is oronym always associated with juncture? If yes, which juncture type is the source of oronyms?

4. Is the model suggested by the study valid and inclusive?

\section{Oronyms: Origin, Definitions and Occurrence}

Etymologically, "oronym" is a Greek word derived from the conjunction of "oro-" meaning (mountain) and "-onym" from "onyma" meaning (name) (2). Oronym is used in geography to designate a mountain or hill and in linguistics it refers to a pair of phrases with the same pronunciation (1). In the latter sense, it was coined by Gyles Brandreth and first published in his classical book The Joy of Lex (1980) (Joshi, 2014). This coinage appeared for the second time in the popular linguistics book The Language Instinct by Steven Pinker where he defines oronyms as "strings of sounds that can be carved into words in two different ways" often used in songs and nursery rhymes (1994: 160). Oronym is defined by Evans (2012) as a string of words or a phrase that sounds the same as another string of words or phrase but is spelt differently. Similarly, Stewart (2015: 237) describes oronyms as "sentences that can be read in two ways with the same sound" as in: The stuffy nose can lead to problems/ The stuff he knows...

Although the term "oronym" has not been mentioned in most dictionaries of linguistic and literary terms such as (Scott, 1985; Bussmann, 1996; Cuddon, 1998; Abrams, 1999; Baldick, 2001; Childs and Fowler, 2006; Quinn, 2006; Crystal, 2008; Murfin and Ray, 2009; Wales, 2014) it has appeared recently in some websites of language games and fun with words. These online sources refer to oronyms as virtually identical speech that can be interpreted in different ways with endless comic possibilities. This speech involves a sequence of words ( $a$ nice) that sounds the same as a different sequence of words (an ice), where phrases with similar pronunciation but different spelling and meanings may be employed $(3 ; 4)$.

As can be seen, most definitions of oronyms are similar in content but are distinct in characterizing the linguistic phenomenon that produces them. Some characterize oronyms as instances of homophones or an extended version of homophones which usually refer to single words that sound alike $(5 ; 6 ; 7)$. Others deal with them as different phrases that can sound identical because of ambiguous word boundaries in speech. More precisely, these phrases are phonetically identical but different in spelling and meaning because they are differently segmented $(1 ; 8 ; 9)$. This may account for naming oronym as a "slice-o-nym" or a "continunym".

Pinker (1994: 159) explains how oronyms occur in his claim that human brain hears speech not as individual words but as a string of sounds in which "one word runs into the next seamlessly; there are no little silences between spoken words the way there are white spaces between written words". For 
him, the seamlessness of speech is apparent in oronyms and the main reason for their occurrence. When run together; "strings of sounds can be carved into words in two different ways" (ibid: 160) as in "a nice/ an ice". Joshi (2014) adds that oronyms also originate when a particular word may be divided into two or more meaningful words, for example, "nitrate" can be taken as a single word "nitrate" or two words "nitrate" and "night rate" because of a pause in between them. Oronyms occur either when there is seamlessness between adjacent words or when a word itself is cut short into two separate words. In both cases, oronyms share a similar sequence of sounds; however, they are composed of words that are cut at different points in the phonetic strings (ibid).

\section{Oronyms: Homophones or Not?}

The lack of consensus about the phenomenon that makes oronyms may cause a confusion and raise a few queries: when two phrases are identical in pronunciation but have different spelling and meaning, are they homophones? If not, what is the linguistic phenomenon that distinguishes phrases such as sick snails/ six nails? This section will identify this phenomenon in an attempt to explicate the mechanism for making oronyms.

Most semanticists designate different words (i.e. lexemes) with the same sound as homophones. For them, two words are homophones if they are pronounced the same way but written differently and often have different meanings such as threw/through, morning/mourning, rite/right/ write/wright (Lyons, 1977: 22, 1995: 55; Lass, 1998:29; Crystal 2008: 231 and Richards and Schmidt 2010: 264). On the other hand, oronyms involve phrases that are accidently homophonic with other phrases. Therefore, six nails/ sick snails that are phonetically identical are made possible by another phenomenon that relies on the speaker running two or more words together rather than separating them or separating them at a different point. In six nails/ sick snails, the two words run together and the boundary between them is not clear where it lies, hence not possible to say with certainty whether a /s/ consonant is at the end of one word or at the beginning of the next. This reinforces Pinker's (1994: 159) view that human brain hears speech not as individual words but as a string of sounds in which "one word runs into the next seamlessly; there are no little silences between spoken words the way there are while spaces between words"

According to Hockett (cited in Rajimwale, 2006: 119), "any difference of sound which functions to keep utterances apart is, by definition, part of phonological system of the language". Pausing between words which may make difference in meaning and spelling is a phonological phenomenon called "juncture". The exact location of juncture often enables the listener to differentiate sick snails from six nails. It is juncture that distinguishes between such phrases and makes them homophonic.

Underscoring the relation between oronyms and juncture, Stewart (2015: 237) defines oronyms as "sentences that can be read in two ways with the same sound" because of junctural equivocation of two or more abutting words as in Are you aware of the words you have just uttered/.....just stuttered. This definition denotes that such phrasal alternatives are predominantly dependent on the wavering phonemic juncture of "transegmental drift" Stewart (1990: 110). Thence, juncture is the linguistic phenomenon that oronyms rely on. Regarding the question "Are oronyms homophones?", the simple answer is "No", since homophones involve words (lexemes) pronounced the same but spelt differently, while oronyms are normally made of phrases with the same pronunciation but different spelling and meaning. Subsequently, it can be said that six nails is not a homophone of sick snails and oronyms are created by the phenomenon of juncture rather than homophony.

\section{Oronymization}

In modern linguistics, juncture indicates "a phonologically manifested boundary between linguistic units" (Lehiste, 1964: 172). For Underhill (1994: 68), juncture is "the label given to a number of features which may occur at the boundary between two words in connected speech. Even though the two words may be fully linked together, the boundary between them is nevertheless unambiguous and clear". 
Crystal (2008: 258) describes it as the phonetic boundary features that may demarcate grammatical units such as morpheme, word or clause. Skandera and Burleigh (2005: 61) hold a similar opinion that, in actual speech, there are phonological and also phonetic features which mark the beginning and the end of linguistic units, or more precisely, signal the boundary between syllables, words, and clauses. For them, those boundary signals are what is called "juncture" and what enables language users to detect a word or a phrase boundary which is seldom marked in the flow of speech. They also explain that there are different ways of realizing juncture. Although pauses are the most obvious junctural features or boundary signals there may be other features marking the beginnings and endings of grammatical units in connected speech. These features are usually of segmental and suprasegmental nature like the occurrence of certain phonemes adjacent to word-boundary, modifications of phonatory patterns i.e., glottal stops insertion and modifications of suprasegmental patterns of fundamental frequency, duration, intensity, lengthening of phonemes in onsets and coda. This is well exemplified by the sequence /jætst $\Lambda \mathrm{f} /$ where word boundary is signaled by a complex of stress, pitch, length, and other features. This way of juncture realization is "the allophonic realization of the phonemes preceding and following the word boundary which makes that word boundary perceptible. It also helps language users recognize the sequence /jætstsf/ as either that stuff or that's tough" depending on the location of the boundary signals whether between /s-t/ or /t-s/. For instance, in that stuff, the word-final / $\mathrm{t} /$ is unaspirated and the word-initial $/ \mathrm{s} /$ is strongly articulated whereas, in that's tough, the word-final /s/ is relatively weak and the word-initial / $/$ / is aspirated. The above example shows that juncture not only signals the boundaries between words but makes the same segmental sequence form more than one morphemic structure. It helps listeners distinguish between phrases that have the same phonemic representation but different patterns in allophonic variations across the word boundary as the example above and other phrases such as peace talks/ pea stalks, tulips/ two lips, that school/ that's cool and others (for more details, see Lehiste, 1964; Hughes, 1969; Nasr, 1997: 45; Keating, 1999; Weber, 1999; Nicolosi et al., 2004: 166; Skandera and Burleigh, 2005: 61 and Crystal, 2008:258).

Juncture contributes to creating homophonic phrases identical in pronunciation but different in meaning and spelling, hence a linguistic mechanism for making oronyms. Here, some questions may be posed: Does this mean that wherever there are junctures, there are oronyms? Is there one type of juncture? If not, which type is the source of oronyms?

In phonology, there are several classifications of juncture. The most common one is the closeopen juncture (Gimison, 1970; Roach, 1983; Crystal, 2008 and Skandera and Burleigh, 2005). Close juncture refers to the normal transitions between segments (sounds) within a word. That is, sounds follow one upon the other closely with no perceptual pause between them ${ }^{1}$. For instance, in the word nitrate there is a close juncture between $/ \mathrm{n} /$ and $/ \mathrm{ar} /, \mathrm{ar} /$ and $/ \mathrm{t} /, / \mathrm{t} / \mathrm{and} / \mathrm{r} /, / \mathrm{r} /$ and $/ \mathrm{eI} /$ and finally /eI/ and /t/. Open juncture, on the other hand, indicates junctural features at a word boundary. It is subdivided into external open juncture and internal open juncture (Roach, 1983 and Skandera and Burleigh, 2005). If the word boundary is preceded or followed by a pause, i.e. at the beginning or at the end of an utterance, it is an external open juncture. For instance, in the word nitrate, $/ \mathrm{n} /$ is preceded by a pause and $/ \mathrm{t} /$ is followed by a pause so $/ \mathrm{n} /$ and $/ \mathrm{t} /$ are said to be in a location of external open juncture. If the word boundary is not preceded or followed by a pause, i.e. the words on both sides of the boundary are run together, it is an internal open juncture. For instance, the sequence night rate has internal open juncture between $/ \mathrm{t} /$ and $/ \mathrm{r} /$, and it is the location of internal open juncture that distinguishes a name from an aim (Skandera and Burleigh, 2005: 62).

Internal open juncture is the only type that creates homophonic phrases as it involves a "special kind of break between phonemes which breaks up the phonemic flow and makes words" (Robert, 1956: 231). Nasr (1997: 45) and Rajimwale (2006: 119) also maintain that the syllable break at the internal open juncture sometimes distinguishes otherwise homophonic phrases or, in Karn and Yeni-Komshians'

${ }^{1}$ According to Skandera and Burleigh (2005: 62), the use of the term "juncture" here is only justified by the fact that there is a kind of "boundary" even between sounds. 
(2005:1) words, dozens of minimal pairs "which contain the same sequence of phonemes but differ in their prosody, meaning and orthography". Therefore, this type of juncture is considered a linguistic mechanism for forming minimal pairs (homophonic phrases), hence oronyms, when such phrases are used wittingly to play upon words.

\section{Wordplay and Oronyms}

Playing upon words has long been one of the most favorite practices of human beings all over the world and throughout decades. It involves any creative and unusual use of language with a purpose beyond the everyday communication of basic information. Crystal (1998, cited in Schröter) points out that when people play with language they manipulate it in a way they take some linguistic features such as a word, a phrase, a sentence, a part of a word, a group of sounds, a series of letters and make it do things it does not normally do. In effect, this cannot be done without bending and breaking the rules of language. Hence, word-players, in their attempt to play upon words, often violate the rule of clarity and intelligibility in language via their reliance on ambiguity as a linguistic strategy to "break down lazy expectations and subvert the inertia of language and thought" (Redfern, 1984: 13-4).

Gillie (1977: 523) defines play upon words as "a use of a word with more than one meaning or of two words which sound the same in such a way that both meanings are called to mind". Punning is regarded as one of the earliest and the commonest forms of wordplay. According to Sherzer (1978:336), punning is "a form of language play in which a word or a phrase unexpectedly and simultaneously combines two unrelated meanings". It, thus, occurs when two meanings competing for the same phonemic space or as one sound yielding forth semantic twins (Hartman, cited in Fried, 1988: 85). Ullmann (1962: 188) shows how polysemy and homonymy have a role in making puns. Similarly, Leech (1969: 209) supports Ullmann's view when defining pun as "a foregrounded lexical ambiguity which may have its origin in polysemy and homonymy". An example to this type of punning is the following pun-based joke in which there is a subtle play on the two meanings of the homonyms "left" and "right" (10):

Trump has two parts of brain, "left" and "right".

In the left side, there"s nothing right.

In the right side, there"s nothing left.

Although these views confirm the reliance of puns on ambiguity, they limit the scope of punning to one type of ambiguity viz. lexical ambiguity arising from words of polysemic or homonymic nature. Marino (1988:43), on the other hand, expands the scope of punning to encompass other structures based on various linguistic phenomena. He opines that pun is "a simple juxtaposition of two meanings that are based on any coincidence of phonology, morphology, syntax, or semantics. Delabastita (1996: 128) underscores this opinion in his description of pun as a form of wordplay that involves "various textual phenomena in which structural features of the language(s) used are exploited in order to bring about a communicatively significant confrontation of two (or more) linguistic structures with more or less similar forms and more or less different meanings". Punsters make full use of the possibilities of ambiguity in the words and other structures of language to produce different types of puns. More precisely, they manipulate not only polysemy and homonymy but other linguistic phenomena that produce structures resembling each other in form (they look or sound the same) but different in meaning.

Writers take advantage of the confusion about the boundaries between words for a subtle play upon words. They make full use of the poetic aspects of the phenomenon of "juncture" to enrich the aesthetic experience of the language with phrases or sentences that can be read in two ways with the same sound (Alkawwaz, 2020: 232). Drawing attention to this use of language, Brandreth (1980) coined the term "oronyms" by indicating a form of wordplay that involves a playful shifting of word boundaries to produce a string of words that can be interpreted in two homophonic ways. Ambiguity created by 
boundary shifting is thus cleverly exploited to provide a rich source of homophonic phrases and then enable a certain form of wordplay called "oronyms" or "oronymic puns".

Such form of wordplay has long been used by punsters, jokers, and song writers before the term "oronyms" appears. Nash (1985: 139) refers to it as a type of pun based on "phrasal homophony". Chiaro (1992:35) describes it as syllabic phenomenon where word boundaries played with "by generating more than one item from what was a single item in the first place by means of the elimination of the original word boundaries". Ermida (2008: 42) categorizes this wordplay as phonetic puns based on juncture.

\section{Methodology}

Though wordplay has got much attention of rhetoricians, folklorists, linguists and literary scholars, oronyms have been overlooked in linguistic research, in that, there has been no model to classify oronyms and analyze their linguistic aspects. This study will set a model for analyzing oronyms. The model is an eclectic one made up of two components to show how oronyms are created and used. The first component relies on that oronyms usually occur either when a word itself cut short into two separate words or when there is seamlessness between adjacent words that makes them heard in two different ways (pinker, 1994 and Joshi, 2014). So, it draws a distinction between word-to-phrase and phrase-to-phrase oronyms. The former is based on creating a new juncture within a word that may produce audibly a different phrase and meaning as in nitrate/night rate. In the latter, when the position of juncture between words changes a new phrase with different meaning and spelling may form as in ice cream/I scream. In both types, there is a common characteristic where "strings of sounds can be carved into words in two different ways" by either creating a new juncture or altering its position between words. The type of juncture, in these two cases, is an internal open juncture whose presence at the syllable break often creates homophonic phrases, and thus oronyms.

The second component of the model is based on the distinction made by Delabastita (1996) who distinguishes wordplay into Vertical and Horizontal. For him, vertical wordplay occurs when two formally similar linguistic structures may clash associatively by being co-present in the same portion of a text as in "The roundest knight at king Arthur's round table was circumference/ Sir Cumference". Horizontal wordplay occurs when the two formally similar linguistic structures are in relation of contiguity by occurring one after another in the text as in "We all scream, for ice cream". On this basis, both word-to- phrase and phrase-to-phrase oronyms will be subdivided into vertical and horizontal as illustrated in the below figure. To uphold the validity of the model, it will be applied to twelve examples of oronyms taken randomly form TV shows, songs, nursery rhymes, and books of jokes and fun words.

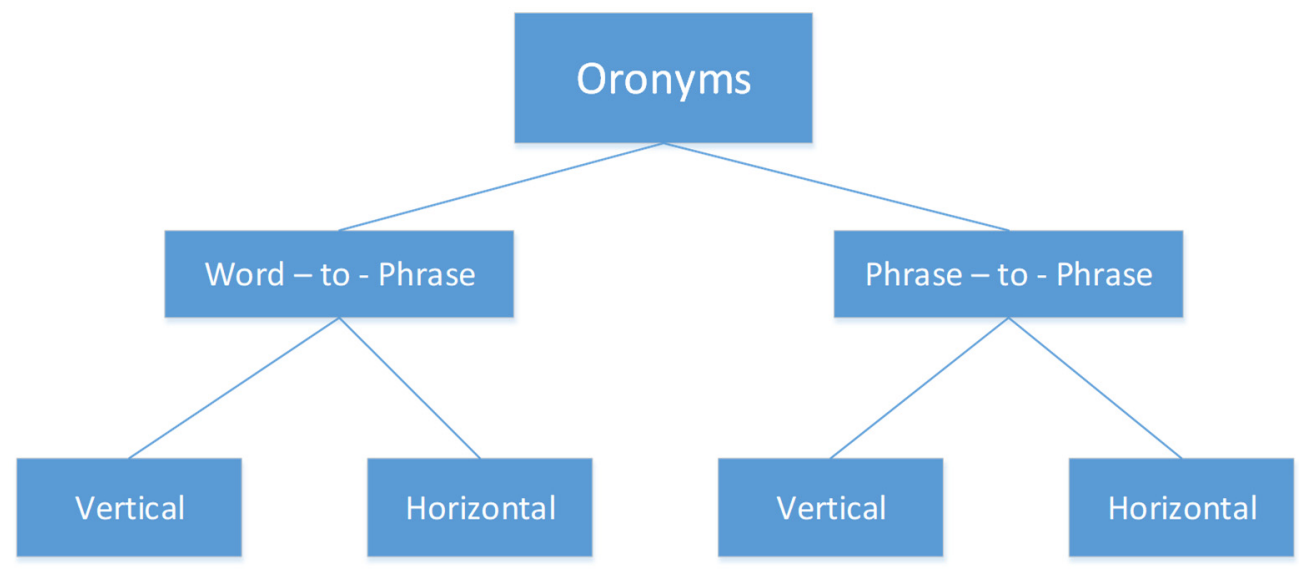

Figure: Phono-Rhetorical Model for Oronyms 


\title{
7. Data Analysis
}

\subsection{Word-to-Phrase Oronyms}

\author{
1. How much wood would a woodchuck chuck \\ if a woodchuck would chuck wood? \\ A woodchuck would chuck \\ All the wood that a woodchuck could chuck, \\ if a woodchuck would chuck wood. \\ (Tucker, 2008: 22)
}

Here, the sequence / wod.t $\int \Lambda \mathrm{k}$ / was used to indicate both a single word "woodchuck" and a verb phrase "would chuck". The difference between these two expressions stems from an internal open juncture that breaks the sequence into two words "would" and "chuck" with difference in meaning and spelling. The writer subtly plays on the absence and presence of juncture in this sequence to invent such amusing oronyms.

2. A: My wife's gone to the West Indies.

B. Jamaica?

A: No-she went of her own accord (11).

In this joke, the wordplay is in B"s answer "Jamaica" whose pronunciation /dzə 'merkə/ can be interpreted in two homophonic ways: a single word referring to the name of an island country in the Caribbean Sea and the American pronunciation of the interrogative sentence "Did you make her?" The joker plays on the phonic- morphological boundaries of words to produce oronyms that conjure up to the mind of the hearer or reader "Jamaica" or "Did you make her?"

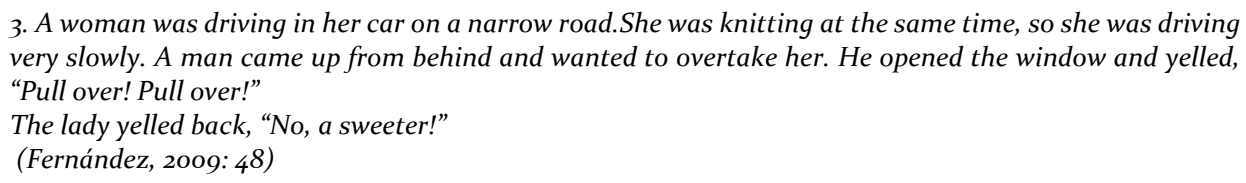

Oronyms, here, are epitomized in the sequence /poləovo/ which can be heard to mean two different expressions: "pullover" as a lexical item refers to a sweater and "pull over" as an imperative phrasal verb. The difference between the two expressions stems from the presence of internal open juncture that breaks the sequence into two words "pull" and "over" and produces another expression of different meaning, spelling and a grammatical category.

4. Man: I'd like to buy a pair of stockings for my wife.

Clerk: Sheer?

Man: No, she's at home.

(Seewoester, 2011: 75)

In this joke, oronyms lie in the clerk's reply "sheer?" which invokes a convoluted parallel between a single word "sheer" and an interrogative sentence made up of three words "Is she here?". Such complex homophony is based on the presence of internal open juncture that breaks down the phonological sequence into three words and produces a completely different expression.

5. The melon wanted to get married in secret, but then she realized she cantaloupe (12).

Oronyms, here, are in the word "cantaloupe" whose pronunciation / 'kæntə, loup/ yields a distant form of homophony between a name of fruit, "cantaloupe", and a negative verb phrase "cannot elope". Such phrasal homophony is established through an internal open juncture that breaks the single word 
and produce a new phrase that shares the same pronunciation but different in meaning, spelling and grammatical category.

6. Question: What did the DJ say at the garden party?

Answer: Lettuce turnip the beet (13)!

There are two pairs of oronyms in the answer of the joke "lettuce/let us" and "turnip/turn up". In each pair, a new juncture is created, converting the single word into a phrase similar in pronunciation but different in meaning, spelling and grammatical category. Those homophonic sequences form an intricate parallel between "lettuce turnip the beet" as three single words referring to three types of vegetables and "let's turn up the beat" as a suggestion to rise up the tune.

\title{
7.2 Phrase-to-Phrase Oronyms
}

\author{
7. I scream, \\ You scream, \\ We all scream for ice cream. \\ (Howard, et al., 1927)
}

These verses are a part of a popular song including a string of oronyms used to play and make fun with words. This type of oronyms is different from the first one as the wordplay is based upon the seamlessness between adjacent words that makes them heard in two different ways. This involves altering the position of internal open juncture between words that may result in a new phrase with different meaning and spelling as in "ice cream" and "I scream".

8. There is this man who meets a fairy. He is granted three wishes. Having wished for his most urgent needs the man uses his third wish to ask the fairy to return and give him three more wishes.

The fairy complies and says: "You can call me whenever you want."

"How can I call you? Please tell me your name." the man says.

"My name is Nuff," says the fairy.

"Well", says the man "That is an odd name. I have never heard of it before."

The fairy replies, "Surely you will have heard of Fairy Nuff."

(Fernández, 2009: 51)

In this joke, the oronym lies in the sequence "Fairy Nuff" where the seamlessness between these two adjacent words suggests an ingenious phrasal homophony "Fairy Nuff" and "fair enough". Such phrases are established because of the internal open juncture location either between "Fairy" and "Nuff" or "fair" and "enough".

9. How is a man clearing a hedge in a single bound like a man snoring?

- He does it in his sleep.

(Kaivola-Bregenhøj, 2001: 131)

This riddle is built on an either-or ambiguity which stems from the confusion over the boundary between the words "his" and "sleep". Such confusion creates the oronyms "his sleep" and "his leap" because of the internal open juncture position.

10. When is it difficult to get your watch out of your pocket?

- When it keeps ticking there.

(Kaivola-Bregenhøj, 2001: 132)

Oronyms are also found in sequence /ki:pstıkıy/ heard in two different ways as "keeps ticking" and "keeps sticking". Such phrasal homophonic pairs come from playing with word boundaries by altering the position of the internal open juncture. 
11. In "The Four Candles" sketch, the setting is a hardware shop. Ronnie Corbett is behind the counter.

Ronnie Baker is the customer:

Baker: Four candles.

Corbett: places four candles on the counter.

Barker: No, four candles!

Corbett: Well, there you are four candles!

Barker: No, fork handles! Handles for forks! (14)

In this sketch, oronyms are exemplified by the sequence /fo:kændl/ interpreted as "four candles" and "fork handle". This phrasal homophony is also created by altering the position of internal open juncture between the adjacent words.

12. Why did cookie cry?

- Because his mother had been away for (a wafer) so long (15).

In this example, oronyms lie in the answer to the riddle where the sequence /əweifə/ can be heard as "away for" and "a wafer". These phrases are made by altering the position of the internal open juncture location either between "away" and "for" or "a" and "wafer".

\section{Discussion}

This study has explored oronyms and investigated their dubious nature, identified a linguistic mechanism for their generation, and put forward a model for analyzing their phonological and rhetorical aspects. To this end, the study has drawn on twelve examples of oronyms categorized into two types: Word-to-Phrase and Phrase-to-Phrase oronyms, six samples for each type. Each type has been subdivided into Vertical and Horizontal.

The analysis has revealed that oronym is a rhetorical device often used in jokes, songs, and nursery rhymes. It involves playful shifting of the boundaries between words. Playing with the phonomorphological boundaries of words usually engenders phrases different in meaning and spelling but similar in sound when spoken. Such phrases are distinguished by internal open juncture whose presence draws an "either-or" ambiguity and thus homophonic phrases. The potentiality of juncture to produce ambiguity endows oronyms a rhetorical value to serve as a great basis for wordplay.

The data analysis has showed that all oronyms rely on the same type of juncture but where and how this juncture occurs are not the same. This substantiates the claim that oronyms can be produced by creating a new juncture or altering its position between words. The first six examples representing the first type explicate how the presence of juncture in a new word contributes to the creation of a distant form of homophony between a single word and a phrase. On the other hand, the second six examples of the second type demonstrate how altering the position of juncture between words gives rise to phrasal homophony. The analysis has also demonstrated that oronyms in examples 2, 3, 4, 5, 6 of the first type and 8, 9, 10, 12 of the second, are packed into one occurrence of a single expression so they are vertical. In contrast, oronyms, in example 1 of the first type and 7,11 of the second are horizontal because of their occurrence one after another in the same text. This indicates that the model established in this study is valid and inclusive.

\section{Conclusion}

The study has displayed that oronym is a rhetorical device combining two ideas in a single sequence of words. It involves a play on phrases that sound alike but differ in spelling and meaning. In this vein, oronyms are more than a pair of phrases that are pronounced similarly, as commonly defined, but a deliberate use of such phrases for humorous purposes. Oronyms are constructed through juncture where the same sequence of sounds can form more than one morphemic structure. As such, juncture acts as a linguistic strategy consciously employed to yield phonological ambiguity required for such a 
variety of wordplay. Among other types of juncture, internal open juncture specifically can serve as a source of homophonic phrases, hence a linguistic mechanism for coining oronyms.

The data analysis has demonstrated that oronyms are of two main types: Word-to-Phrase and Phrase-to-Phrase oronyms. In the first type, the presence of internal open juncture creates a phrasal homophony between a single word and a phrase, whereas in the second its presence establishes a convoluted parallel between homophonic phrases. In both cases, there is an either-or ambiguity that misleads the hearer or reader. The analysis has also shown that oronyms can be Vertical or Horizontal according to their occurrence in each selected example. Accordingly, each type of oronym can be subdivided into vertical and horizontal. Therefore, the model adopted here is effective and workable.

This study has, thus, explored the linguistic features of oronyms exhaustively and has laid a theoretical foundation for examining oronymy phenomenon even in other languages. A prospective study can examine oronyms, for instance, in Arabic language, and Iraqi folk poetry where it is profusely used.

\section{References}

Abrams, M. H. (1999). A Glossary of Literary Terms. USA: Heinle \& Heinl.

Alkawwaz, S. (2020). Juncture as a Poetic Device. In: International Journal of Innovation, Creativity and Change, Volume 13, Issue 1, pp. 225-239.

Attardo, S. (1994). Linguistic Theories of Humor. Berlin: Mouton de Gruyter.

Attardo, S., D. Attardo, Paul Baltes and Ma. Jo Petray (1994). The linear organization of jokes: analysis of two thousand texts. In: Humor 7(1): 27-54.

Baldick, Ch. (2001). The Concise Oxford Dictionary of Literary Terms. New York: Oxford University Press Inc.

Brandreth, G. (1980). The Joy of Lex: How to Have Fun with 86o,341,50o Words. USA: William Morrow \& Co.

Bussmann, H. (1996). Dictionary of Language and Linguistics. London: Routledge.

Chiaro, D. (1992). The Language of Jokes Analyzing Verbal Play. London: Routledge.

Childs, P. and R. Fowler (2006). The Routledge Dictionary of Literary Terms. London: Routledge.

Crystal, D. (2008). A Dictionary of Linguistics and phonetics. USA: Blackwell Publishing Ltd.

Cuddon, J. (1998). Dictionary of Literary Terms \& Literary Theory. London: Penguin Books.

Delabastita, D. (1996). Wordplay and Translation. Special Issue of The Translator: Studies in Intercultural Communication. Manchester: St. Jerome Publishing.

Ermida, I. (2008).The Language of Comic Narratives: Humor Construction in Short Stories. Berlin: Walter de Gruyter GmbH \& Co. KG.

Evans, R. (2012). Tyrannosaurus Lex: The Marvelous Book of Palindromes, Anagrams, and Other Delightful and Outrageous Wordplay. USA: Penguin Putnam Inc.

Fernández, G. (2009). English Jokes for ESL Students. Spain: Lulú Press Inp.

Fried, D. (1988). Rhyme Puns. In: Culler, J. (ed.), On Puns: The Foundation of Letters, pp. 83-99. New York: Basil Blackwell.

Gillie, Ch. (1977) A Companion to British Literature. London: Longman Group Ltd.

Gimison, A. (1970). An Introduction to the Pronunciation of English. London: Edward Arnold.

Johnson, H. Moll, B. and R. King (1927). I scream, you scream, we all scream for Ice Cream: Popular Standard, Single Songbook. Roba Digital Sheets.

Joshi, M. (2014). Oronym Words in English: Vocabulary Building. USA: Create space Independent Pub.

Hughes, J. (1969). The science of Language: An Introduction to Linguistics. USA: Random House.

Kaivola-Bregenhøj, A. (2001). Riddles: Perspectives on the use, function and change in a folklore genre. Helsinki: Finnish Literature Society.

Karn, H. and yeni-Komshian, G. (1995). "Acoustic Phonetic Characteristics of Internal Open Juncture by Mexican Spanish Speakers (A)". In: Journal of Acoustical Society of America, Vol. 97, Issue 5, P. 3384.

Keating, P., Wright, R. and J. Zhang (1999). "Word- level Asymmetries in Consonant Articulation". UCLA Working Papers in Phonetics, 97: 157-173.

Lass, R. (1998). Phonology: An Introduction to Basic Concepts. Cambridge: Cambridge University Press.

Leech, G. (1969). A Linguistic Guide to English Poetry. London: Longman Group Ltd.

Lehiste, I. (1964). “Juncture”. Proc. $5^{\text {th }}$ int. Congr. Phon. Sci., Munster, pp. 172-20o.

Lyons, J. (1977). Semantics. London: Cambridge University Press.

Lyons, J. (1995). Linguistic Semantics: An Introduction. London: Cambridge University Press. 
Marino, M. (1988). Puns: The Good, The Bad and The Beautiful. In: Humor, 1-1, pp. $39-48$.

Murfin, R. and S. Ray (2009). The Bedford Glossary of Critical and Literary Terms. New York: Bedford/ St. Martins. Nasr, R. (1997). Applied English Phonology: for ESL/EFL teachers. Lanham, Md.: University Press of America.

Nash, W. (1985). The Language of Humor: Style and Technique in Comic Discourse. London: Longman Group Ltd. Nicolosi. L., Harryman, E. and J. Kresheck (2004). Terminology of Communication Disorders: Speech-LanguageHearing. Lippincott Williams \& Wilkins.

Pinker, S. (1994). The Language Instinct: The New Science of Language and Mind. London: Penguin Books.

Quinn, E. (2006). A Dictionary of Literary and Thematic Terms. New York: Facts on File, Inc.

Rajimwale, Sh. (2006). Handbook of Linguistic Terms. New Delhi: Sarup \& Sons.

Redfern, W. (1984). Puns. New York: Basil Blackwell.

Richard, J., Platt, J. and H. Weber (1985). Longman dictionary of applied linguistics. England: Longman.

Richard, J. and R. Schmitt (2010). Longman Dictionary of English Language Teaching and Applied Linguistics. London: Pearson Education Limited.

Roach, P. (1983). English Phonetics and Phonology: A practical course. Cambridge: Cambridge University Press.

Schröter, T. (2005). Shun the Pun, Rescue the Rhyme? The Dubbing and Subtitling of Language Playin Film. (Doctoral dissertation). Karlstad University, Karlstad.

Scott, A. (1985). Current Literary Terms. London: The Macmillan Press Ltd.

Seewoester, S. (2011). "The role of syllables and morphemes as mechanisms in humorous pun formation". In Dynel, M. (ed.), The Pragmatics of Humor across Discourse Domain, pp. 71-104. USA: John Benjamins Publishing Company.

Sherzer, J. (1978). Oh! That's a pun and I didn't mean it. In: Humor, 12 (2): 119-149.

Skandera P. and P. Burleigh (2005). A Manual of English Phonetics and Phonology: Twelve Lessons with an Integrated Course in Phonetic Description. Tübingen: Gunter Narr Verlag.

Stewart, G. (1990). Reading Voices: Literature and the Fonotext. California: University of California Press.

Stewart, G. (2015). The Deed of Reading: Literature * Writing * Language * Philosophy. Ithaca \& London: Cornell University Press.

Tucker, E. (2008). Children's Folklore: A Handbook. London: Greenwood Press.

Ullmann, S. (1962). Semantics: An Introduction to the Science of Meaning. Oxford: Basil Blackwell.

Underhill, A. (1994). Sound Foundations. Oxford: Macmillan Publishers Limited.

Wales, K. (2014). A Dictionary of Stylistics. New York: Routledge.

Weber, A. (200o). "Phonetic and Acoustic Cues for Word Segmentation in English". In Proceedings of the 6th International Conference on Spoken Language Processing (ICSLP): pp. 782-785.

\section{Websites}

https://en.wikipedia.org/wiki/Oronym

https://www.lexico.com

https://www.thoughtco.com/what-is-an-oronym-1691461

https://allthingslinguistic.com/post/73883817409/fun-with-english-oronyms-linguistics-girl

https://englishgarden.forumotion.com/t6774-oronyms-and-homophones

https://literarydevices.net/homophone/

http://www.fun-with-words.com/nym_words.html

https://katexic.com/word/oronym/

https://www.businessballs.com/amusement-stress-relief/puns-and-double-meanings/

https://joke4fun.com/text/trump-has-two-parts-of-brain-19112

https://languagelog.ldc.upenn.edu/nll/?p=591

https://yellowjokes.com/melon-jokes

https://wischoolgardens.org/monthly-garden-jokes/

https://www.youtube.com/watch?v=Ozpek_FrOPs

https://www.goodbadjokes.com/jokes 